\title{
EDENISMO TERRITORIAL, ANACRONISMO TÉCNICO E A IDEALIZAÇÃO DO PROGRESSO NO BRASIL IMPERIAL
}

\section{TERRITORIAL EDENISM, TECHNICAL ANACHRONISM AND THE IDEALIZATION OF PROGRESS IN IMPERIAL BRAZIL}

\author{
Gilvan Charles Cerqueira de Araújo ${ }^{1}$ \\ Secretaria de Educação do Distrito Federal/Universidade de São Paulo \\ gilvan.cerqueira@edu.se.df.gov.br
}

\section{Resumo}

Este artigo busca explorar reflexões envolvendo o edenismo territorial e o anacronismo técnico no período imperial brasileiro. Entende-se que o estudo deste período histórico e sua importância para a formação do território nacional do Brasil se configuram como um profícuo campo de perscrutações teórico-analíticas por diferentes campos do conhecimento em dialogia com o pensamento geográfico, envolvendo uma melhor compreensão das ações, reflexões e desdobramentos de importantes acontecimentos atinentes à ideologia do progresso e ao ufanismo telúrico em relação ao território nacional. Por meio de uma revisão bibliográfica, é proposto um aprofundamento destas questões em três momentos complementares: iniciase o debate pelos reflexos territoriais do anacronismo imperial e republicano; passa-se pela temática do desenvolvimento técnico do período imperial e ufania edênica e se encerra com a relação entre a ocupação do território brasileiro e o anacronismo técnico.

Palavras-chave

Edenismo; Anacronismo Técnico; Território; Brasil Império.

\begin{abstract}
The main objective of this article is to explore reflections involving the territorial edenism and technical anachronism in the Brazilian imperial period. This paper assumes the perspective that the study of this historical period and its importance for the formation of the national territory of Brazil is configured as a profitable field of theoretical and analytical insights through different fields of knowledge in dialogue with geographical studies, involving a better understanding of actions, debates and developments of important events regarding the ideology of progress and the telluric jingoism related to the national territory. Therefore, a bibliographic review has been realized as a proposal to deepen these questions in three complementary steps, beginning with the territorial reflexes of imperial and republican anachronism, followed by the theme of technical development in the imperial period and Edenic jingoism and ending with the relationship between occupation of Brazilian territory and technical anachronism.
\end{abstract}

\footnotetext{
${ }^{1}$ Possui graduação em Geografia pela Universidade Estadual Paulista Júlio de Mesquita Filho (2009) mestrado em Geografia pela Universidade de Brasília (2013) e doutorado em Geografia (Organização do Espaço) pela Universidade Estadual Paulista Júlio de Mesquita Filho (2016). Pós-doutorando em Geografia, Literatura e Filosofia pela Universidade de São Paulo. ORCid: https://orcid.org/0000-0003-4238-0139 


\section{Ensaios de Geografia}

Essays of Geography | POSGEO-UFF

Keywords

Edenism; Technical Anachronism; Territory; Empire of Brazil.

\section{Introdução}

Este artigo se constitui como uma versão adaptada da primeira parte do terceiro capítulo da dissertação de mestrado em Geografia defendida pelo autor intitulada "Do Ufanismo Edênico ao Saudosismo Heroico: ideologia e discurso geográfico no ideário nacional brasileiro" no ano de 2013, pela Universidade de Brasília. Objetiva-se com esta ação a maior divulgação do trabalho em destaque e, também, um movimento de maior amplitude e divulgação da temática do edenismo e ufania telúrica ao longo da formação territorial do Estado nacional brasileiro.

Por meio de uma revisão bibliográfica, ao longo do artigo será efetuada uma relação teórica e analítica entre o discurso ufanista edênico em relação ao território brasileiro e o período histórico imperial, marcado por questões concernentes a um anacronismo técnico, promovido direta e indiretamente pelas visões e ações econômicas, políticas e ideológicas deste contexto (IANNI, 2004; PENNA, 1974). Este será o ponto de partida do debate proposto que se apresenta, buscando contemplar o panorama territorial que vai do ufanismo edênico ao cenário econômico e técnico no Brasil imperial às características históricas, geográficas e econômicas (CASTRO, 2005; GAUDIO, 2007; HOLANDA, 2010; RANGEL, 1981).

Algo a ser destacado é justamente esta nova relação entre o homem e o meio que o circunda a partir de uma consideração analítica, histórica e geográfica do período, por exemplo, da contextualização da segunda fase da Revolução Industrial, que chega ao Brasil a partir da implantação de vias férreas pelo território. No decorrer do século XIX este contexto ficará mais claro devido às ondas nacionalistas europeias, em especial na Alemanha e Itália, que gerarão a elaboração de teorias filosóficas, históricas, sociológicas e geográficas cuja principal palavra de ordem será o domínio ou dominação da natureza (BRASIL, 2008; CASTRO, 2005, MIYAMOTO, 1995, MORAES, 2005). Atreladas à premissa de dominação, farão coro às ideias de conquista, ou seja, não bastava mais apenas a posse de extensas terras, como o foi nos primeiros três séculos de colonização, 


\section{Ensaios de Geografia}

Essays of Geography I POSGEO-UFF

havia de se fazer valer a presença deste poder, era preciso promover a interiorização do princípio de territorialização outrora colonial, mas agora já com alguns incrementos técnicos e tecnológicos alinhados à concepção e prática político-econômica do império brasileiro.

$\mathrm{Na}$ esteira da perspectiva dominadora e conquistadora de recursos naturais, base para o discurso e ufanismo edênico, soma-se a aclamação progressista, alimentada pelo sonho da missão histórica do ser humano no domínio sobre a Terra e seus recursos naturais. Na Geografia, este cenário do século que alcança os fins XIX e o início do século XX será mais visível no nascimento de algumas das primeiras contribuições teóricas de natureza geopolítica, nutrida pala visão determinista (CASTRO, 2005, MIYAMOTO, 1995, MORAES, 2005). Nas outras áreas do conhecimento ver-se-á um retorno às antigas proposições de preponderância étnica numa concepção desnivelada da situação técnica dos povos, enquadrando-os desta maneira em diferentes estamentos civilizacionais (EAGLETON, 2005). Uma nova modulação de entendimento do conhecimento como via de acesso ao poder entra em cena, no caso geopolítico, claramente visível no Brasil Imperial. Isto se mostrará numa melhor apuração delimitativa das fronteiras, na execução de guerras a possíveis ameaças externas e, principalmente, no aumento significativo de organizações, grupos e instituições responsáveis por angariar informações a respeito do território. O discurso contemplativo dá lugar à palavra de ordem da dominação não apenas pela exploração desenfreada, mas pela implantação técnica de transformação do espaço (CARVALHO, 2003; CASTRO, 2005).

Deste modo, havia um cenário distributivo das vias de fluidez territorial influenciando o incentivo às expedições científicas para avanço do conhecimento dos aspectos sociais e naturais do território: a crise do sistema político monárquico arcaico para uma república tardia e retrógrada nos aspectos técnicos; o surgimento das primeiras iniciativas de um pensamento geográfico incipiente e genuinamente brasileiro e a permanência das velhas formas de pensamento a respeito do Brasil em sua permanência no ideário mítico da destinação providencial (IANNI, 2004; MORAES, 2004).

Os reflexos territoriais do anacronismo imperial e republicano 


\section{Ensaios de Geografia}

Essays of Geography | POSGEO-UFF

No território colonial e posteriormente na fase imperial do Brasil havia demonstrações de um uma rica cultura popular arraigada a aspectos religiosos e tradicionais, como foi o caso da arquitetura barroca, exemplo de uma expressão artística de fronteira - a mescla entre a opulência aristocrática expressa nos adornos eclesiásticos e a simplicidade material e abrangência simbólica de alto alcance das obras populares em madeira e pedra - e também nas inúmeras insurgências principalmente literárias de cunho valorativo das principais características regionais presentes em todo território brasileiro como na primeira geração dos literatos românticos (CANDIDO, 1989; CITELLI, 2004).

Estes acontecimentos culminarão na complexa passagem do século XIX para o século XX, onde ficarão explícitas questões de alto teor analítico para compreendermos alguns dos rumos tomados pelo Brasil. A começar pelo processo de independência, no qual de ruptura houve apenas o sentido retórico, perdurando a continuidade do poder central por parte dos dois imperadores do país - Dom Pedro I e Dom Pedro II - havendo inclusive importantes situações de embates bélicos em ambos os governos contra seus dissidentes ou contraditores. Concomitante a este período, será assistido o processo de renovação agrícola, fornecendo mais um fôlego à já secular classe latifundiária brasileira (BRASIL, 2008). E, por fim, novos apelos surgirão, em especial, no quesito social, por parte de literatos, artistas, lideranças regionais, políticos e clérigos; estes apelos culminarão na inevitável pressão interna e externa pela abolição da escravatura, no rompimento político com os descendentes da família portuguesa e a fundação de um regime republicano (em tese renovador) e na vigente e temerária situação de anacronismo técnico, cada vez mais efusiva em todos os níveis produtivos e aspectos da economia brasileira (HOLANDA, 1969; PRADO JÚNIOR, 2006).

Iniciemos, pois, nossa reflexão partindo do panorama situacional no qual se encontrava o Brasil durante seu período imperial, marcado pelo processamento lento e faseado em direção à independência do país e, também, pela renovação econômica trazida pelas lavouras de café no sudeste do país (FURTADO, 1991). Após este caráter introdutório será dada uma atenção especial ao panorama técnico do território brasileiro no período imperial, assim como às iniciativas políticas para a reversão de tal quadro. Desta propensão à tecnificação do Brasil é que emergirá, por exemplo, a grande 


\section{Ensaios de Geografia}

Essays of Geography | POSGEO-UFF

quantidade de expedições científicas, principalmente de caráter naturalista, por todo território brasileiro.

Todo o processo vivido pelo Brasil no início do século XIX possui peculiaridades históricas incomparáveis internacionalmente. De início, pode-se levar em consideração a surpreendente ação de fuga da família real para sua colônia maior, contando para tal empresa com o total e irrestrito apoio inglês - posteriormente retribuído com calorosos beneficiamentos comerciais. Também é digno de ser destacado o processo de independência do Brasil, que surge como um projeto de união constitucional entre colônia e metrópole e acaba tendo como resultado a separação umbilical de ambos, apesar de ainda permanecer em solo brasileiro o herdeiro da coroa portuguesa (BRASIL, 2008; FURTADO, 1991; HOLANDA, 1969).

A partir do momento em que a trupe reinol atraca no litoral carioca, uma nova fase de implicação técnica ocorre no Brasil. As preocupações do então primeiro príncipe - em situação de regência desde 1799 - do trono lusitano Dom João VI serão de imediato tomar iniciativas burocráticas de viabilização da retomada comercial, manufatureira e estrutural para com a colônia, além da ascensão política e estatal do Brasil devido à transferência da corte (RICUPERO, 2008).

Tais medidas podem ser agrupadas cronologicamente pela Carta Régia de 28 de janeiro de 1808, que eliminava o secular pacto colonial com a abertura dos portos às "potências" e "nações amigas"; a revogação do Alvará de 3 de dezembro de 1785, emitido por D. Maria I, que proibia a existência de qualquer produção de natureza manufaturada em território colonial (apesar de que isto não beneficia o Brasil diretamente, pois o Tratado de Comércio e Navegação de 1810, resultado de negociações bilaterais vigentes desde 1808, privilegiava explicitamente a entrada de produtos ingleses frente aos demais estrangeiros e aos de Portugal); ascensão do Brasil da condição de vice-reinado a reino autônomo em 16 de dezembro de 1815, com o título de Reino Unido de Portugal, Brasil e Algarves ${ }^{2}$.

\footnotetext{
2 Para visualização de amostras destes documentos históricos em seu formato original ver: <www.iuslusitaniae.fcsh.unl.pt. > Acesso: 08 dez. 2012. 


\section{Ensaios de Geografia}

Essays of Geography | POSGEO-UFF

Em especial no Decreto de Abertura dos Portos às Nações Amigas de 1808, o que há de fato é a derrocada do sistema pactual da colônia com sua metrópole. Isto, a longo prazo, levaria às inevitáveis turbulências políticas que resultaram no processo de independência: "No Brasil, um desenvolvimento linear e irreversível marca a passagem do sistema anterior para o dos direitos preferenciais e a consolidação deste último: a carta régia desfecha o golpe mortal no monopólio.” (RICUPERO, 2008, p. 18).

A desvinculação entre colônia e metrópole fará com que a primeira passe a seguir seus próprios rumos político-econômicos. O pensamento do período imperial - e aqui se inclui a fase regencial do mesmo - seguirá os ditames do curto período de poder de Dom João VI. O foco de ação política dos governantes será a unidade de centralização do poder da nobreza e a continuidade do incentivo econômico a produtos de origem agropecuária ou de extração natural - haverá a transferência do ciclo da cana-de-açúcar pelo período cafeeiro, e no minguar das remanescentes jazidas de ouro a atenção se voltará à extração da borracha na floresta amazônica (PRADO JÚNIOR, 2006).

Apesar da concessão de liberdade produtiva de itens manufaturados fornecida em 1810, em nenhum momento o foco dos mandatários imperiais e nem dos representantes agropastoris será o desenvolvimento técnico de ordem industrial que já se espalhava por outros países para além das ilhas britânicas, como Itália, França, Japão e Estados Unidos (HOLANDA, 1969; RICUPERO, 2008).

Mantendo então o seu foco produtivo no setor primário, o Brasil caminhava para seu próprio curso histórico apartado de Portugal. No entanto, entrará em cena o processo de independência brasileiro, implicando alterações e especificidades produtivas a partir desse momento. Em termos gerais, é possível entrelaçar alguns fatores que delinearam tal acontecimento. Já desde 1799 o então príncipe regente D. João Maria de Bragança recebia pressão por parte da corte portuguesa para assumir o lugar de sua mãe, D. Maria, principalmente após sua coroação em 1816. A fuga para o Brasil corroborou o aumento da divisão entre apoiadores e detratores da equalização entre a colônia e a metrópole (BRASIL, 2008).

A Revolução do Porto de 1820 foi o ponto limite onde o rei português retornou para a Europa. Por fim, por motivo da grande pressão da aristocracia brasileira - 


\section{Ensaios de Geografia}

Essays of Geography | POSGEO-UFF

principalmente aquela localizada nos estados de Rio de Janeiro e São Paulo - para que houvesse o desligamento do país de Portugal e que fosse proclamada a independência, tal fato acaba por se concretizar em 7 de setembro de 1822, sendo então D. Pedro I nominado em 12 de outubro de 1822 Imperador do Brasil (BRASIL, 2008; HOLANDA, 1969; RICUPERO, 2008). Este fato foi uma das tentativas brasileiras de entrar no ritmo da história, tornando-se independente e procurando se alinhar aos discursos libertários das revoluções burguesas do final do século XVIII. Tal pretensão não se consumaria durante todo o século XIX, como ressalta Ianni (2004): "Em 1822 o Brasil não conseguiu entrar no ritmo da história." (IANNI, 2004, p. 13).

Esta breve recapitulação histórica se faz necessária para que possamos nos localizar em relação à importância deste fato ao Brasil. Esta peculiaridade deve-se à imediata condição de litígio e situações belicosas passadas pelo novo Imperador logo após sua proclamação de independência (CASTRO, 2005; MORAES, 2005; MORAIS, 2004).

Também foram designadas diversas condições monetárias para que a apartação se finalizasse, houve pontos de resistência à independência no Nordeste e, além disso, era preciso levar a notícia da nova condição política aos quatro cantos do país. A Inglaterra aparece neste momento como principal financiadora do processo de independência do Brasil, fomentando os custos e apoio bélico ao novo imperador. E esta dependência numa "troca" de uma metrópole direta (a portuguesa) para uma indireta, representada pelos ingleses, é um dos principais pontos de atenção deste período:

\footnotetext{
Nenhuma nação se emancipa comprando a sua independência a peso de ouro, e nem o seu governo é cedido em legado, como aconteceu no Brasil, e por este fato pode-se chamar a D. Pedro I, fundador do Império, que a Nação o comprou "ignominiosamente" por 2 milhões de libras esterlinas!? (MORAIS, 2004, p. 304).
}

No mais, cabe lembrarmos que o já citado princípio de territorialização (BASTOS, 2008, CASTRO, 2005) se fez presente nos primeiros anos do Brasil independente. Os conflitos armados foram comuns e numerosos: "O reinado de D. Pedro I foi de lutas, de calamidades, de dissipações e de desatinos. A corrupção governamental e a dissipação das rendas públicas, e servilismo, foram inaugurados neste reinado." (MORAIS, 2004, p. 307). Podemos citar como exemplos destes conflitos: A Confederação do Equador (18231824), A Guerra da Cisplatina (1825-1828) e a Revolta dos Mercenários (1828). 


\section{Ensaios de Geografia}

Essays of Geography I POSGEO-UFF

A disputa pelo poder e os interstícios políticos pela legitimação, jurisprudência e exercício deste poder no período imperial no Brasil foram fatos perenes até a coroação de Pedro de Alcântara, primogênito de D. Pedro I, como segundo imperador. Os conflitos continuaram na regência e no decorrer da segunda metade do século XIX.

Conforme nos lembram Prado Júnior (2006), Ricupero (2008) e Holanda (1969; 1984), entre a independência e as primeiras décadas do segundo império tivemos talvez o período politicamente mais instável da história do Brasil; conflitos estouravam em toda a extensão do território por motivos que variavam da reivindicação de independência separatista, como a Guerra dos Farrapos, no Rio Grande do Sul (1835-1845), por afirmação religiosa, como no caso da Revolta dos Malês, na Bahia (1835), ou contrariedade às condições sociais de trabalho do operariado das lavouras cafeeiras na Fazenda de Ibicaba, em São Paulo (1857).

$\mathrm{Na}$ bandeira imperial do Brasil podemos observar um esboço do que viria a ser a nossa atual representação heráldica republicana. Um dado interessante sobre tal representação é que a raiz de suas cores estava ligada principalmente à ascendência das famílias reais de D. Pedro $\mathrm{I}^{3}$, característica esta mantida no modelo republicano contemporâneo. No entanto, com a continuidade das formas geométricas e cores até a atual bandeira nacional, tais cores com o acréscimo do azul acabaram por tomar um significado popular de ligação com as características naturais do Brasil, verde com as florestas, o amarelo com o ouro e o azul com o céu, com a adição das estrelas e constelações do céu.

O Império brasileiro teve duração de mais de oito décadas (1822-1889), e durante este período houve fatos e situações históricas que nos possibilitam homogeneizá-lo enquanto continuidade dos ditames sociais, econômicos e políticos da fase precedente, ou seja, centralização do poder político, economia baseada na produção agrícola, forte

\footnotetext{
3 "A simbologia desta bandeira se fundamenta nas cores escolhidas e proclamadas pelo próprio D. Pedro I, o verde e o amarelo, "a riqueza e a primavera eterna do Brasil." A cor verde estava desde o tempo da Revolução Portuguesa de 1640 na história lusa, marcando o início da dinastia de Bragança da qual Pedro de Alcântara era herdeiro; o amarelo deveu-se à Casa de Habsburgo-Lorena, família imperial da Áustria, através de D. Maria Leopoldina, esposa de D. Pedro I e filha do Imperador Francisco II. Convém citar que a forma de losango, desde o tempo de D. João I de Portugal, estava ligada às Armas das Damas, pois este formato era utilizado como suporte dos brasões femininos; o escudo com esta configuração era chamado de escudo feminino." (SEYSSEL, 2006, p. 87).
} 


\section{Ensaios de Geografia}

Essays of Geography | POSGEO-UFF

influência cultural europeia - especialmente os cenários artísticos inglês e francês - e insurgências sociais contrárias aos imperadores (D. Pedro I e D. Pedro II) ao longo de suas figurações à frente do comando governamental no Brasil. A diferenciação principal entre os dois períodos serão as implementações tecnológicas a partir de meados do século XIX, como as ferrovias e os telégrafos (BRASIL, 2008; FURTADO, 1991).

Dos fatos mais notáveis passíveis de análise na segunda fase do período imperial brasileiro podemos destacar também o grande desenvolvimento rural no sudeste, isto na segunda metade do século XIX por meio da instauração da produção cafeeira com suas altas taxas de importação, assim como o declínio do regime escravocrata, em parte devido à pressão internacional, onde o cenário já era de superação do uso da mão-de-obra escrava. Internamente, houve importantes iniciativas provindas da parcela letrada da população apresentando posicionamento contrário ao modo de produção escravista vigente no país havia quase quatro séculos, sendo inclusive o último país americano independente a conceder liberdade aos seus escravos. Sobre o avanço da produção agrícola no período imperial temos que:

Dois fatos (aliás, intimamente relacionados) a constituem; um de natureza
geográfica: é o deslocamento da primazia econômica das velhas regiões
agrícolas do Norte para as mais recentes do Centro-Sul (o Rio de Janeiro e
partes limítrofes de Minas Gerais e São Paulo). Outro é a decadência das
lavouras tradicionais do Brasil - da cana-de-açúcar, do algodão, do tabaco -, e
o desenvolvimento paralelo e considerável da produção de um gênero até então
de pequena importância: o café, que acabará por figurar quase isolado na
balança econômica brasileira. (PRADO JÚNIOR, 2006, p. 157).

Em contraposição à dinamização econômica necessária e urgente, por conta da decadência dos antigos produtos comercializados no Brasil, havia o posicionamento mantenedor por parte de D. Pedro II de sua condição totalitária frente aos assuntos políticos do império (BRASIL, 2008; HOLANDA, 1969; MORAIS, 2004). Apesar de haver-se instaurado em 1847 o regime parlamentarista, havia desde a Carta Magna de 1824 a presença do Poder Moderador, colocado acima da tríade jurídica formada pelo Legislativo, Judiciário e Executivo, e garantidor de toda a potência ordenatória dos mandos e desmandos do monarca brasileiro.

A defesa do centralismo do Poder Moderador era aquiescida veementemente por José de Bonifácio, um dos preceptores de D. Pedro II, e importantes autores, como José 


\section{Ensaios de Geografia}

Essays of Geography I POSGEO-UFF

de Alencar (1997) em seu Systema Representativo de 1868, reiteravam a importância da neutralidade do Poder Moderador acima dos outros poderes (BRASIL, 2008). Em contrariedade a este centralismo havia a Escola de Recife, da qual fizeram parte nomes como Capistrano de Abreu (1853-1927), Graça Aranha (1868-1931) e Silvio Romero (1851-1914), tendo como um de seus expoentes Tobias Barreto (1839-1889); outro importante fomentador de ideais republicanos foi Tavares Bastos (1997), como se nota em sua obra de 1870, A Província, quando declama: "Longe vão esses tempos belicosos em que fora a unidade garantia da independência, condição da força e grandeza. Una e indivisível parecia então dever ser a própria república.” (BASTOS, 1997, p. 31).

O período do segundo Império nos apresenta uma gama considerável de importantes elementos, políticos e econômicos, que juntos fornecem o núcleo necessário para uma análise a respeito da maneira como o pensamento da época se comportava em relação ao Brasil. De um lado há a manutenção da grandeza edênica, agora desconfigurada de seu romantismo e vista como obstáculo hostil frente à corrida pelo progresso; e do outro a imposição centralizadora da cultura aristocrática na figura do imperador em postura de obsessão pelo ingresso do Brasil no plantel dos principais países do cenário mundial do século XIX:

\footnotetext{
O país parece enveredar pelo caminho da ruptura. E quanto mais as coisas se fragmentam, mais a elite brasileira, bem como o sistema político no seu todo, parecem tomados por uma exasperação que Bosi chama de "obsessão do descompasso", aquela que mede a distância entre Brasil e as sociedades capitalistas avançadas. Tal obsessão domina a mente de economistas, políticos, homens de mídia, empresários e professores universitários, expressando-se como a síndrome da modernização. A modernização é necessária, urgente e crucial; numa palavra: a salvação. (SANTOS, 1998, p. 23, grifo do autor).
}

Juntamente com a obsessão modernizadora, o ufanismo edênico perpetuado pelos românticos renova-se, fortalecendo os objetivos de dominação e conquista presentes no naturalismo da época. Nas palavras de Afonso Celso em seu livro Porque me ufano do meu país de 1881: "Devem ter ufania os filhos de uma terra assim dotada. O belo é a fonte essencial do amor. Amemos apaixonadamente o Brasil, pelas suas lindezas sem par. A riqueza do Brasil é proporcional à sua extensão e à beleza: extraordinária.” (CELSO, 1997, p. 62-63). 


\section{Ensaios de Geografia}

Essays of Geography | POSGEO-UFF

Ainda segundo o próprio autor, sobrevinha à necessidade do ufanismo a disposição divina de nosso destino: "Somos filhos de um bondoso, sadio, robusto colosso. Refere a Bíblia que Saul foi proclamado rei, por ser mais alto que todo o seu povo do ombro para cima.” (CELSO, 1997, p. 31). Também vemos tal sublimação hiperbólica em Maria Graham em seus diários datados de 1824: "Se o embaixador de Nápoles que disse a Jorge III que a lua de seu país valia o sol da Inglaterra tivesse estado no Brasil, eu quase poderia perdoar a hipérbole." (GRAHAM, 1990, p. 237). E o mesmo discurso de surpresa existe em Louis Agassiz (2000), em 1868, quando este relata incrédulo a grandeza dos rios amazônicos em suas profundidades colossais.

A questão do desenvolvimento técnico e tecnológico e o edenismo territorial brasileiro

No pensamento da segunda metade do século XIX haverá a influência de movimentos literários e de viés filosófico fortemente influenciados pela harmonização do ser humano para com seus iguais e com o ambiente em que vive, com destaque ao grupo formado pelos socialistas utópicos de Charles Fourier (1772-1837) Saint-Simon (17601825), Louis Blanc (1811-1882) e Robert Owen (1771-1858). Há outras obras paradigmáticas deste período, como Moby Dick (1851), de Herman Melville, e Caninos Brancos (1910), de Jack London, que nos ajudam a compreender este panorama de reverência sublime à natureza, ao mesmo tempo em que são externados os desejos de domínio frente a tal hostilidade selvagem. No primeiro caso há o embate pela vida, enquanto no segundo há o ato de domação do ser selvagem. Nas palavras de Eagleton (2005), consuma-se a ideia de civilizar a criatura hostil; são diferentes pontos de vista em relação ao embate entre o homem e a fera, uma herança romântica entre o sublime e o monstruoso (CITELLI, 2004).

A questão colocada é: de que maneira é possível observarmos esta contraposição entre o dantes romântico para o agora realista e naturalista posicionamento frente às riquezas do Brasil? E a resposta a tal questionamento será a ciência, ou seja, o conhecimento e a técnica, a construção prática da instrumentação tecnológica necessária para se fazer real o sonho da conquista e a concretização do domínio dos desafios da 


\section{Ensaios de Geografia}

Essays of Geography | POSGEO-UFF

natureza frente à vontade e razão humana: "Em geral, dentro da nossa cultura, a Ciência é responsável pelo desenvolvimento e manutenção dos conhecimentos sobre a natureza e a vida, suas leis e sua lógica, e a Tecnologia cuida de seus usos." (VIDAL, 1988, p. 71). O fator técnico será o diferencial. Era preciso dinamizar o território, propiciar condições para que o desenvolvimento da economia se transformasse, pois os períodos de glória da extração aurífera há muito haviam se esgotado e a concorrência na produção da cana-deaçúcar com as Antilhas era um fato inegável (ANTUNES, 1975; MORAES, 2005).

Analisemos, portanto, a profundidade conceitual e histórica de algumas nuanças terminológicas da técnica. Assim chegar-se-á no seu papel de transformação do espaço geográfico e, no que tange especificamente ao Brasil imperial, será o centro motriz de toda uma forma de pensar, pois sua existência, especificidade e desenvoltura será a condição necessária para a execução do domínio espacial do território brasileiro.

A técnica é, portanto, o meio pelo qual a transformação do mundo se torna possível. O entendimento da técnica como abstração, concreção e processo, por seu papel incisivo na produção do espaço e no decurso da história é marcante. O que se verifica é a objetivação do pensamento e da vontade por meio do domínio técnico fomentado pelo conhecimento científico e tecnológico: "En sentido amplio, deve entenderse por técnica toda práctica que se torna posible mediante la objetivación teórica del ente. Lo que llamamos tecnificación presupone siempre la reducción de mero objeto llevada a cabo por la ciencia natural exacta con el ente.” (MEYER, 1966, p. 192). E ainda sobre a técnica em seu processo de avanço pelo conhecimento científico temos que: "A tecnologia necessita da ciência, a qual constantemente a alimenta. Aquela é de maior abrangência política, enquanto a Ciência é principalmente de natureza cultural e tem no meio acadêmico o seu albergue natural." (VIDAL, 1988, p. 71).

Transpondo tais colocações para o campo do pensamento geográfico é possível restringirmos o papel da técnica, da tecnologia e do pensamento científico como viabilizador do encurtamento das distâncias na aceleração do tempo de circulação de pessoas, mercadorias e informações:

O avanço tecnológico também minimiza o papel da distância nas interações espaciais. É isto que, sistematicamente, tem ocorrido de modo crescente a partir da Revolução Industrial, viabilizando interações mais rápidas e mais 


\title{
Ensaios de Geografia \\ Essays of Geography | POSGEO-UFF
}

eficientes, envolvendo cada vez mais maiores volumes de mercadorias a distâncias maiores em menor tempo e custo. (CORRÊEA, 1997, p. 302).

A procura pelo avanço técnico visava o aumento da comunicabilidade entre os diferentes pontos do território brasileiro. Conforme nos lembra Moraes (1999), era preciso interligar as "ilhas" populacionais espalhadas pelo Brasil. Milton Santos (1996) chamará esta dinâmica interacionista de relação entre os fixos e os fluxos, que significa a localização dos pontos produtores e exportadores, além das localidades urbanas em concomitância com as vias de acesso entre estes pontos, por rodovias, ferrovias e hidrovias:

\begin{abstract}
As técnicas participam na produção da percepção do espaço, e também da percepção do tempo, tanto por sua existência física, que marca as sensações diante da velocidade, como pelo seu imaginário. Esse imaginário tem uma forte base empírica. $\mathrm{O}$ espaço se impõe através das condições que ele oferece para a produção, para a circulação, para a residência, para a comunicação, para o exercício da política, para o exercício das crenças, para o lazer e como condição de "viver bem". Como meio operacional, presta-se a uma avaliação objetiva e como meio percebido está subordinado a uma avaliação subjetiva. Mas o mesmo espaço pode ser visto como o terreno das operações individuais e coletivas, ou como realidade percebida. Na realidade, o que há são invasões recíprocas entre o operacional e o percebido. Ambos têm a técnica como origem e por essa via nossa avaliação acaba por ser uma síntese entre o objetivo e o subjetivo. (SANTOS, 1996, p. 55).
\end{abstract}

A presença das ilhas populacionais era o sinal latente do anacronismo brasileiro, principalmente no que dizia respeito à interligação de seu imenso território (MAGNOLI, 1997). O atraso técnico era uma realidade no Brasil imperial, registrada nas crônicas dos viajantes e sentida em cada núcleo urbano ou lavoura: “[...] em tudo que usamos ferramentas são empregadas aqui as mãos nuas dos negros" (GRAHAN, 1990, p. 237). O mais importante é que o incentivo às expedições científicas partia do próprio imperador. Em face de sua participação na Exposição Científica Universal, na Filadélfia em 1876, sobre os aspectos naturais e sociais, D. Pedro II via nitidamente a questão deste atraso no qual o Brasil se encontrava e a necessidade de superação desta imagem frente aos norteamericanos, já em processo de industrialização, e aos europeus. Um dos seus objetivos, portanto, era:

Retirar a imagem de "reino distante e selvagem" e instaurar definitivamente o país entre as nações civilizadas e modernas. O fato de ser uma monarquia escravocrata, tropical e mestiça impedia isso. Nas várias participaçõos 


\section{Ensaios de Geografia \\ Essays of Geography | POSGEO-UFF}

brasileiras nessas feiras o que se ressaltou foram os aspectos exóticos e agrários do país, nunca seus aspectos "modernos". (BASTOS, 2008, p. 48-49).

Trazendo as experiências internacionais pautadas pelas mais recentes correntes de pensamento da época, como o positivismo, o evolucionismo e o determinismo ambiental, D. Pedro II tentará instaurar alguns destes avanços no Império. Em outros termos, verifica-se um intenso processo de territorialização a partir do argumento e ação da presença da técnica nos processos produtivos ou interesses específicos, sempre alinhados ao contexto político e econômico. No caso brasileiro a simbologia desta modernidade técnica será representada pela chegada e expansão das linhas férreas, já interiorizadas no projeto econômico nacional de intensificação da produção cafeeira, como novo foco produtivo do país.

O projeto de desenvolvimento técnico e tecnológico em meio ao processo de ocupação e formação territorial do Brasil imperial

A secularização do domínio humano dos recursos naturais tomava nova roupagem na contextualização político-econômica do prosseguimento do processo industrial ao redor do mundo, e nesta trilha histórica o Brasil se mostrava em posição inercial - lembremos que houve uma tentativa pretérita de trazer tais ideias com o Marquês de Pombal, no século XVII, mas que foi prontamente anulada pela retomada do poder central português da época - portanto: "O sistema visado pelo esclarecimento é a forma de conhecimento que lida melhor com os fatos e mais eficazmente apoia o sujeito na dominação da natureza". (ADORNO; HORKHEIMER, 1985, p. 72).

Estas teorias científicas e filosóficas eram as herdeiras do esclarecimento e da ode à racionalidade científica do século XVIII. Durante a modernidade, e seguindo à risca tais diretrizes era preciso trazê-la ao Brasil e assim assumir de fato o domínio territorial do império que representava:

Se o modernismo significava, entre outras coisas, a sujeição do espaço a propósitos humanos, a ordenação e o controle racionais do espaço como parte integrante de uma cultura moderna fundada na racionalidade e na técnica, e na supressão de barreiras espaciais e da diferença, tinham de ser fundidos com alguma espécie de projeto histórico. (HARVEY, 1992, p. 254). 


\section{Ensaios de Geografia Essays of Geography | POSGEO-UFF}

O projeto histórico do Brasil era a ideia de domínio e expansão do conhecimento sobre seu território, pensamento este que já vigorava na segunda metade do século XIX com algumas das principais teorias geopolíticas germânicas e anglo-saxãs (CARVALHO, 2003) que influenciaram a Geografia brasileira da época. Esta influência da geopolítica germânica é extensível ao Brasil " [...] notadamente onde a dimensão espacial parece jogar importante papel nas formas de legitimação do poder estatal.” (MORAES, 2005, p. 109), pois, conforme exposto, a manutenção do Poder Moderador tinha como predisposição a necessidade de um centralismo de D. Pedro II, viabilizado pelo aumento das vias de acesso, comunicação e circulação do império. Ou seja, o território como sinônimo de da força do Estado ${ }^{4}$, unidade matriz do pensamento político, estratégico e geográfico da segunda metade do século XIX:

Em sua origem, ao contrário da atualidade, a geografia política se colocou o compromisso de compreender o modo pelo qual a política era influenciada pela geografia. No final do século XIX, quando da sua institucionalização como ramo da geografia, a geografia política procurou na natureza o marco teórico para explicação da vida política. A tradição do determinismo da natureza na disciplina foi, na realidade, um prolongamento de uma velha preocupação dos filósofos, entre eles Montesquieu, sobre a possibilidade de explicar a fluidez da vida política com argumentos fundados em fatores estáveis, quase imóveis, como meio físico. Por muitas décadas tentou-se mostrar como a distribuição dos continentes e oceanos, cadeias de montanhas, rios, climas e outras características da superfície da Terra afetavam o modo pelo qual a humanidade dividia o mundo em Estados e Impérios e como estas unidades competiam entre si por poder e influência. (CASTRO, 2005, p. 18-19).

O aumento do controle do território para o seu fortalecimento se fez então por esta busca pela técnica enquanto chave deste objetivo. Segundo Santos (1996), Moraes (2005) e Sodré (1984) este é o efeito da produção e organização do espaço, sua modulação de acordo com os interesses dominantes e preponderantes da sociedade que o habita e que o transforma, na construção dos objetos (fixos) das vias de circulação (os fluxos) e na

\footnotetext{
${ }^{4}$ Nas palavras de Shiguenoli Miyamoto: "O determinismo esteve presente em todas as suas colocações. O espaço e a posição - noções retiradas de Ratzel - ocuparam lugar importante para entender a equação geral do Brasil'. Esta visão era a base da geopolítica da época, calcada segundo o autor no controle e manipulação do solo, do clima e do homem. Estes eram os fundamentos ideários fomentadores e sustentadores de toda a ação política no Brasil durante os períodos colonial e imperial: "Na ótica geopolítica, a história brasileira se caracterizou, todo o tempo, por ser expansionista, ora pela política colonial das entradas e bandeiras, ora pela ocupação de territórios no período imperial, com posterior negociação na República, quando praticamente todos os problemas fronteiriços do Brasil foram solucionados.” (MIYAMOTO, 1995, p. 53, grifo do autor).
} 


\section{Ensaios de Geografia \\ Essays of Geography | POSGEO-UFF}

produção de ideias (as ações, ideologias, e formas de pensamento). Portanto, geograficamente:

[...] esse domínio surge justamente da singularidade do homem em eficazmente tornar elementos da natureza extensões de si mesmo. Assim ele projeta nas coisas naturais, que lhe são exteriores, suas necessidades interiores. E assim ele constrói a sua humanidade. E concomitantemente constrói marcas, artefatos que se estendem ao seu redor, cumprindo funções. Esses objetos concretizadores e plenos de intencionalidade humanas formam os lugares. São geografias. Extensos humanos. (SANTOS, 1986, p. 28).

É importante frisarmos um alerta sobre a questão do discurso, do poder e do entendimento de geopolítica. Isto significa dizer que o conhecimento geográfico produzido em um determinado período da história não estará alheio às influências da forma de pensar desta época. Tal posicionamento é partilhado por Castro quando diz que:

Para além do debate sobre o determinismo na geografia, é impossível ignorar que o conhecimento produzido por qualquer disciplina certamente poderá ser apropriado e utilizado pelo poder - por qualquer poder. Neste sentido, é importante reconhecer os limites ideológicos do debate em torno dos modos de apropriação do conhecimento geográfico pelos poderes instituídos e não confundir a geografia, ciência que se propõe dar a conhecer o espaço da humanidade, com os geógrafos e seus interesses como atores intelectuais, sociais e muitas vezes políticos. (CASTRO, 2005, p. 66).

Tendo como pressuposto esta cautela interpretativa dos discursos históricos e seus fundamentos ideológicos, podemos observar claramente a concreticidade da assimilação das ideias da época por parte de D. Pedro II, pois a visibilidade do quadro retrógrado do Brasil em comparação com o restante do mundo se mostrava cada vez mais gritante. Apesar de manter os sinais do tempo pretérito do padrão econômico do país, principalmente por meio da manutenção do regime escravocrata, o imperador trará estas novidades técnicas ao Brasil, como, por exemplo, o telégrafo, as linhas férreas e o incentivo à instalação de manufaturas. Vejamos algumas das principais ações do imperador para com o aumento dos meios de circulação do território brasileiro:

O aparelhamento técnico se desenvolvera bastante. As estradas de ferro, cujo estabelecimento data de 1852, somavam cerca de $9.000 \mathrm{~km}$ de linhas de tráfego, e outros 1.500 em construção. A navegação a vapor se estendera largamente, e além das linhas internacionais, articulava todo o longo litoral brasileiro desde o Pará até o Rio Grande do Sul [...]. Esta navegação somava ao redor de $50.000 \mathrm{~km}$ de linhas em tráfego regular. (PRADO JÚNIOR, 2006, p. 196). 


\section{Ensaios de Geografia}

Essays of Geography I POSGEO-UFF

Estas ações efetuadas por D. Pedro II tinham por objetivo um alinhamento desigual (MAGNOLI, 1997; MORAES, 1986). De um lado havia um país escravista, atrasado em seu sistema econômico integralmente rural e fortemente marcado pela dispersão regional de lideranças aristocráticas que dominavam o cenário político. Do outro começa a haver uma clara pressão pela ordenação progressista da economia, no patamar historicamente ruralista e escravagista, de modo a ser alcançado o desenvolvimento técnico ocorrido desde a Revolução Industrial inglesa no século XVIII: "O progresso quantitativo da cultura cafeeira no Brasil não foi, contudo, acompanhado de igual progresso qualitativo. Continuarão sendo empregados, mais ou menos, os mesmos processos agrícolas rudimentares do passado." (PRADO JÚNIOR, 2006. p. 227).

Estes processos agrícolas estavam interligados, de forma que o auge e queda de ambos foi concomitante onde houve a presença do café como ponto de produção e importância econômica no Brasil, principalmente na região Sudeste. Além de a produção cafeeira ter trazido ao Brasil as ferrovias, houve outro fato importante na segunda metade do século XIX, conforme aponta Scarlato:

O café e a ferrovia foram, por sua vez, importantes fatores de criação de cidades no Sudeste brasileiro. [...] Deve-se ressaltar que, se a economia e a política criaram os estímulos para a fundação dessas cidades, o sítio e a situação definiram o lugar para sua implantação e crescimento. As condições favoráveis do relevo, os bons solos e o clima, juntamente com os sistemas de transportes, definiram aqueles lugares. (SCARLATO, 2005, p. 423).

Por isso, concomitante ao grande incremento econômico trazido pela produção do café foi a fundação de diversas cidades no interior dos estados beneficiados pela produção cafeeira, no caso São Paulo, Paraná e Rio de Janeiro, formando novas lideranças, e dando início a uma nova dinâmica de produção espacial desvinculada dos centros urbanos litorâneos e destoados também das já obsoletas municipalidades localizadas nas Minas Gerais (SCARLATO, 2005). Sobre a importância da produção do café para estas regiões, inclusive já dando os indícios de onde se iniciaria o futuro processo de industrialização do país, Hildete Pereira Melo (2008) reitera a respeito da produção cafeeira:

O café vai caminhando para o interior do país. O deslocamento da fronteira de expansão do café a partir do Vale do Paraíba seguiu duas direções, uma para as terras roxas do Oeste Paulista e a outra caminhou nas terras fluminenses no sentido do Norte em direção a Minas Gerais e o Espírito Santo. Até a Abolição da Escravatura (1888) a Zona Rio tinha a hegemonia nacional como porto 


\section{Ensaios de Geografia Essays of Geography | POSGEO-UFF}

exportador de café. Na segunda metade do século XIX o café iria provocar uma profunda revolução econômica em São Paulo, transformando-a na mais opulenta região do País. (MELO, 2008, p. 53).

A produção do café no Brasil também representava em certa medida a vitória de alguns importantes incentivadores desta produtividade, como o Barão de Mauá (18131889), que em 1854 inauguraria a primeira ferrovia brasileira, a Imperial Companhia de Navegação a Vapor e Estrada de Ferro de Petrópolis ${ }^{5}$. Também podemos citar a figura de Teófilo Benedito Ottoni (1807-1869), importante empresário fluminense que incentivava desde a criação de empreendimentos empresariais e industriais no Brasil até a introdução de um espécime vegetal de difícil adaptação às hostilidades de uma terra tropical.

É evidente que apesar de ter uma distribuição territorial concentrada nos estados de Rio de Janeiro, São Paulo, e regiões sul de Minas Gerais e Espírito Santo, a produção do café, assim como antes fora a exploração do ouro, carregará consigo toda uma dinâmica de ações no espaço que circundava os seus centros de produção, distribuição e consumo, como também a totalidade do Brasil - a distribuição das ferrovias ainda influenciou muitas das rotas rodoviárias dos dias atuais nesta região.

Interessante ressaltar que o capital agenciado pelos produtores de café alcançou tamanho patamar que menos de duas décadas após a derrocada dos grandes produtores deste gênero agrícola (entre 1940-1960), muitos destes antigos barões se tornaram os incentivadores, investidores ou proprietários das primeiras empresas representantes do que viria a ser o início do processo de industrialização do Brasil.

E isto sem contar é claro a herança das diversas cidades situadas ao longo da passagem das vias férreas responsáveis pelo carregamento da produção cafeeira, um sistema citadino visível ainda hoje ao longo da originária trilha do café na região. Nas

\footnotetext{
${ }^{5}$ No livro "A Carne” Júlio Ribeiro pela voz de Manuel nos apresenta um rico relato deste período, neste caso em relação à ferrovia Santos-São Paulo, e seu funcionamento funicular: "Divide-se a subida da serra em quatro planos uniformes de dois quilômetros cada um. Para a tração, empregou-se um sistema adotado em algumas minas de carvão da Inglaterra. Máquinas fixas de grande força recolhem e soltam um cabo fortíssimo, feito de fios de aço retorcidos. Presos as duas pontas desse cabo giram dois trens: um sobe, outro desce. A agulha de um odômetro indica com exatidão matemática o lugar do plano em que se acham os trens, indica o momento de encontro de ambos eles. Um brake de força extraordinária permite suspenderse a marcha quase instantaneamente, e um aparelho elétrico põe os trens em comunicação imediata com as respectivas máquinas fixas. $\mathrm{O}$ cabo, resfriado ao sair por um filete de água, corre sobre roldanas que se revolvem vertiginosas, com um ruído monótono, metálico, por vezes forte, por vezes muito suave. (RIBEIRO, 1972, p. 100).
} 


\section{Ensaios de Geografia}

Essays of Geography I POSGEO-UFF

trilhas e trilhos do café havia o desenvolvimento daqueles que estavam envolvidos com a produção cafeeira, tanto em sua importância interna como externa, para a exportação.

Mesmo com a chegada das primeiras ferrovias nas zonas cafeeiras tal cenário não se alterou significativamente. Este desequilíbrio era o desnível entre o tempo histórico e o tempo real, ou seja, o período da segunda metade do século XIX era o da mudança dos modais de transporte e combustível em todo o mundo - as ferrovias, o vapor, os primeiros motores de combustão, e a telegrafia - enquanto na vida cotidiana dos brasileiros tais avanços eram quase inexistentes

Algumas décadas depois do Império, tal opinião a respeito da desigualdade temporal e material ainda perdurava: "O Brasil avançava materialmente, aproveitava-se dos benefícios da civilização, mas, no plano da cultura, não renunciava ao passado." (BRITO, 1971, p. 32). O trabalho escravo, a precariedade dos engenhos, a insalubridade dos centros urbanos, a extrema dependência do financiamento monetário anglo-saxão e a manutenção de uma economia primordialmente monocultora (o café) eram o espelho de tal situação do Brasil no século XIX ${ }^{6}$.

Apesar de seguir claramente os ditames da demanda produtiva do sistema capitalista industrial da época - o caso brasileiro enquadrado no grupo dos países exportadores de matérias-primas às potências europeias -, em certo sentido houve um considerável aumento do aparato técnico disponível na época para a ligação destes pontos, concretizando a interação espacial entre as principais cidades do litoral com os vastos interiores, todos interligados de alguma maneira à ordem econômica internacional:

As interações espaciais contextualizadas e tornadas inteligíveis na sociedade capitalista a partir do desvendamento da dimensão espacial do ciclo de reprodução do capital, apresentam padrões distintos no espaço e no tempo. Em outras palavras, os diferentes fluxos que articulam os fixos socialmente criados são caracterizados por lógicas que lhes conferem regularidades espaçotemporais que se reportam à organização social e a seu desigual movimento de transformação. (CORRÊA, 1997, p. 285).

\footnotetext{
6 “[...] ao fim do século XIX o Brasil ainda parecia viver no fim do século XVIII. As estruturas jurídicopolíticas e sociais tornaram-se cada vez mais pesadas. Revelaram-se heranças carregadas de anacronismo. Eram evidentes os sinais de uma mentalidade formada nos tempos do colonialismo português. A relação dos setores dominantes e do próprio governo com a sociedade guardava os traços do colonialismo." (IANNI, 2004, p. 19).
} 


\section{Ensaios de Geografia}

Essays of Geography I POSGEO-UFF

A despeito deste certo alinhamento internacional, estas transformações espaciais dos países latino-americanos carregavam em sua sombra o espectro das fábulas e mitos europeus datados da época colonial. De terra prometida passava-se para um conceito de vir-a-ser, uma perseguição ao futuro, daí advém a queda ao discurso da busca pelo progresso, da ocupação necessária do território hostil e selvagem, do fazer valer para si e aos outros o real valor da grandeza dos países abaixo da linha do equador de colonização ibérica:

Quando os latino-americanos despertam (no século XIX) para a consciência nacional, não encontram pronta uma base mítica que lhes servirá para tentar reivindicar como próprio, o passado, para tentar desculpar ou mascarar o fracasso relativo da América Latina, filha do Bom Selvagem, esposa do Bom Revolucionário, mãe predestinada do Homem Novo." (RANGEL, 1981, p. 29).

Outras nuanças discursivas, ideológicas e históricas são passíveis de análise quando o olhar se volta ao período destacado, o século XIX e suas transições de pensamento e complexidade historiográfica no que dizia respeito ao processo de formação territorial, das fronteiras internas e ao edenismo secular que acompanhava as visões em relação ao território brasileiro.

Com isto, a escolha pela especificidade do cenário imperial brasileiro justifica-se como amplo campo de discussão de diferentes embates temáticos da época, o anacronismo e o progresso, o conservadorismo burguês, o radicalismo naturalista, etc. Há obras importantes que marcaram a passagem do ideário idealista romântico para uma postura de maior crítica da sociedade da época como Memórias Póstumas de Brás Cubas (1881) e Quicas Borba (1891), ambas de Machado de Assis, no Brasil, o pioneiro Madame Bovary (1856), de Gustave Flaubert, e as obras já inflamadas pelo realismo de derrocada da belle époque, como A Carne (1888), de Júlio Ribeiro e O Cortiço (1890), de Aluísio de Azevedo (CANDIDO, 1989).

Nas obras supracitadas há a permanência do ufanismo edênico como afirmação nacional na terceira geração romântica, que apesar de pessimista dava continuidade ao espírito romanesco do século XIX, mas a visão realista começava a tomar conta da produção literária da época, como reflexo do cenário econômico e político do país. 


\title{
Ensaios de Geografia
}

Essays of Geography I POSGEO-UFF

Neste sentido de renovação do sublime romântico pela racionalidade realista e naturalista, os relatórios faunísticos, florísticos, hidrológicos e geológicos dos viajantes davam outro teor ao edenismo, agora pautado na mensuração da real grandeza do Brasil, até mesmo para servir de suprimento teórico às instalações técnicas almejadas pelos governantes. Para além da aclamação mística, era preciso dar vigor técnico na aplicabilidade dos objetivos de dominação de toda a riqueza disponível:

\begin{abstract}
É preciso considerar, particularmente nas nações recém-independentes, o fato que exaltar a natureza passou a ser sinônimo de afirmação nacional; de certo modo, o romântico confundiu os conceitos de terra e nação, a dimensão física e a dimensão política. Se a terra era boa, a nação também teria que ser. Por isso, aquilo que possuía uma dimensão vegetal ganhou eficácia ideológica. As florestas viraram símbolos de uma virtualidade: o Brasil, por exemplo, poderia vir a ser, com a majestade de sua natureza, uma espécie de paraíso do futuro. (CITELLI, 2004, p. 79).
\end{abstract}

Tanto no movimento romântico como no realista haverá também uma nova maneira de encarar a situação escravagista do Brasil. Dentro destes posicionamentos realistas antimetafísicos, o positivismo sem dúvida foi o mais expressivo, e era de se esperar que partissem daqueles que apoiavam tal teoria: "Aos tradicionais argumentos fornecidos pelo pensamento ilustrado, pelas doutrinas da economia clássica e pelo romantismo somavamse agora argumentos oriundos do positivismo" (HOLANDA, 1969, p. 181).

O próprio Machado de Assis (2012) protesta por meio de seu conto A Sereníssima República (1882) as idiossincrasias das formas de governo, do processo de elaboração das leis, da jurisprudência e do centralismo de decisão dos representantes do poder executivo. E este era também um dos principais traços do governo imperial, onde a oligarquia regional continuava a exercer seus plenos poderes - apesar de durante toda a República Velha o coronelismo ter continuidade - sendo principalmente um regime marcado pela paradoxal situação técnica, social e política, quadro este que começará a se alterar paulatinamente a partir dos militares da República da Espada, culminando posteriormente na sucessão dos presidentes mineiros e paulistas durante as primeiras décadas do século XX. Ao que parece este cenário de contradição e paradoxo entre o discurso futurista e progressista, dos responsáveis pelas cadeiras de decisões, e a realidade objetiva estrutural do país perpetua até os dias atuais. 


\section{Ensaios de Geografia}

Essays of Geography | POSGEO-UFF

\section{Considerações Finais}

O estudo da prática e do discurso edênico se torna emergente e de primeira importância por sua perenidade e complexidade na historiografia brasileira, como trabalhado por Gaudio (2007) e Buarque (2010). O fato de ter encontrado nas fronteiras do Brasil sua concretude simbólica, acaba por alastrar o edenismo regional e temporalmente entre usos, ideologias e difusões da potencialidade da visão do paraíso terreal americano (ARAÚJO, 2019; 2020).

A alteração do status político do Brasil em sua elevação inicialmente a Reino Unido, depois a Vice-reino, já no final do período aurífero, e por fim em seu processo de independência trará profundas mudanças ao país. No que tange ao nosso interesse de natureza geográfica, a principal característica desta fase será uma nova roupagem ao ufanismo edênico, ainda contemplativo, mas se manifestando muito mais como um princípio de dominação sustentado pela necessidade de um avanço técnico no trato com espaço geográfico, (re)produzindo-o e alterando-o, numa relação dialética entre o natural, as formas espaciais pretéritas e as novas estruturas construídas.

Portanto o presente trabalho vem oferecer uma contribuição reflexiva a respeito desta temática. Em específico no que diz respeito ao período imperial brasileiro, é possível encontrar, conforme demonstrado, uma gama considerável de elementos que comprovam grande parte da força econômica, social e simbólica da territorialismo edênico, que ainda possui outras temáticas, tanto em um escopo mais concentrado como também em áreas mais correlatas, que dialogam com o imaginário e ideologia edênicos, como é o caso da ciência geográfica.

\section{Referências}

ADORNO, T. W.; HORKHEIMER, M. Dialética do Esclarecimento: fragmentos filosóficos. Trad. Guido Antonio de Almeida. Rio de Janeiro: Zahar Editora, 1985.

AGASSIZ, L.; AGASSIZ, E. C. Viagem ao Brasil (1865-1866). Trad. Edgar Süssekind de Mendonça. Brasília: Senado Federal Conselho Editorial, 2000.

ANTUNES, C. Problemas e Perspectivas: elementos de Geografia Física, Social e Econômica do Brasil. 2a Ed. Petrópolis: Editora Vozes, 1975. 
ARAÚJO, G. C. C. Ideologia Espacial e Ufania Edênica. GEOGRAFIA EM QUESTÃO (ONLINE), v. 12, p. 37-53, 2019.

ARAÚJO, G. C. C. O imaginário canônico americano e os símbolos edênicos. Élisée Revista de Geografia da UEG, v. 9, p. 1-24, 2020.

ASSIS, M. A Sereníssima República. Disponível em: <http://www.dominiopublico.gov.br/download/texto/bv000239.pdf>. Acesso em 3 dez. 2012.

BASTOS, T. A. C. A Província: estudos sobre a descentralização no Brasil. $3^{\text {a }}$ Ed. Rio de Janeiro: Comissão de Publicações/Academia Brasileira de Letras, 1997.

BASTOS, M. R. Retratos do poder imperial no Brasil. In: Revista FACOM, n. 19, v. 1, 2008.

BRASIL. Brasil: Império dos Trópicos. Curadoria e textos de Cláudia Beatriz Heynemann e Maria do Carmo Teixeira Rainho. Rio de Janeiro: Arquivo Nacional, 2008.

BRITO, M. S. História do modernismo brasileiro: antecedentes da Semana de Arte Moderna. $3^{\text {a }}$ Ed. Rio de Janeiro: Civilização Brasileira, 1971.

CANDIDO, A. Formação da Literatura Brasileira. V. 1 e 2. São Paulo: Martins, 1989.

CARVAlho, J. M. Teatro das Sombras: a política imperial. Rio de Janeiro: Civilização Brasileira, 2003.

CASTRO, I. E. Geografia e Política: território, escalas de ação e instituições. Rio de Janeiro: Bertrand Brasil, 2005.

CELSO, A. Porque me ufano do meu País. Rio de Janeiro: Expressão e Cultura, 1997.

CITELLI, A. Romantismo. $3^{\text {a }}$ Ed. São Paulo: Editora Ática, 2004.

CORRÊA, R. L. Interações Espaciais. In: CASTRO, I. E; GOMES, P. C. C; CORRÊA, R. L. (Orgs). Explorações Geográficas. Rio de Janeiro: Bertrand Brasil, 1997.

EAGLETON T. A ideia de cultura. Trad. Castello S. São Paulo: Editora Unesp, 2005.

FURTADO, C. Formação Econômica do Brasil. São Paulo: Editora Nacional, 1991.

GAUDIO, Rogata Soares Del. Ideologia nacional e discurso geográfico sobre a natureza brasileira. Belo Horizonte: Editora UFMG, 2007. 


\section{Ensaios de Geografia}

Essays of Geography I POSGEO-UFF

GRAHAM, M. Diário de uma viagem ao Brasil. (1824). Trad. Américo Jacobina Lacombe. Belo Horizonte: Editora Universidade de São Paulo, 1990.

HARVEY, D. A condição pós-moderna. Trad. Adail Ubirajara Sobral \& Maria Stela Gonçalves. São Paulo: Edições Loyola, 1992.

HOLANDA, S. B. História Geral da Civilização Brasileira: Reações e Transações. $2^{\mathrm{a}}$ Ed. $3^{\circ}$ Vol. Tomo III. São Paulo: Difusão Europeia do Livro, 1969.

HOLANDA, S. B. Visão do Paraíso: os motivos edênicos no descobrimento e Colonização do Brasil. São Paulo: Companhia das Letras, 2010.

IANNI. O. A ideia de Brasil Moderno. São Paulo: Editora Brasiliense, 2004.

MAGNOLI, D. O corpo da pátria. São Paulo: Moderna/EDUNESP, 1997.

MELO, H. P. A Zona Cafeeira: uma expansão pioneira. Revista Brasileira de Gestão e Desenvolvimento Regional, v. 4, n. 3, , p. 49-82, 2008.

MEYER, H. J. La Tecnificación del Mundo: origen, essencia y peligros. Trad. Rafael de La Vega. Madrid: Editorial Gredos S. A., 1966.

MIYAMOTO, S. Geopolítica e poder no Brasil. Campinas/SP: Papirus, 1995.

MORAES, A. C. R. Território e História do Brasil. São Paulo: Editora Annablume, 2005.

MORAIS, A. J. M. A. Independência e o Império do Brasil. Brasília: Senado Federal, 2004.

PRADO JÚNIOR, C. História Econômica do Brasil. São Paulo: Brasiliense, 2006.

RANGEL, C. Do bom selvagem ao bom revolucionário. Trad. Berenice de Souza Otero. Brasília: Editora Universidade de Brasília, 1981.

RIBEIRO, J. A Carne. São Paulo: Editora Três, 1972.

RICUPERO, R. Introdução In. RICUPERO, R.; VALENTE DE OLIVEIRA, L. (Orgs.). A abertura dos portos. São Paulo: Senac, p. 1-30, 2008.

SANTOS, C. O conceito de extenso (ou a construção ideológica do espaço geográfico). In: SANTOS, M., SOUZA, M. A. (Orgs.). A construção do espaço. São Paulo: Nobel, p. 25-31, 1986. 


\section{Ensaios de Geografia}

SANTOS, L. G. Tecnologia, natureza e a "redescoberta" do Brasil. In: ARAÚJO, H. R. (Org.) Tecnociência e Cultura: ensaios sobre o tempo presente. São Paulo: Estação Liberdade, 1998.

SANTOS, M. A Natureza do Espaço: Técnica e Tempo, Razão e Emoção. São Paulo: Editora Hucitec, 1996.

SCARLATO, F. C. O espaço industrial brasileiro. In: ROSS, J. Geografia do Brasil.

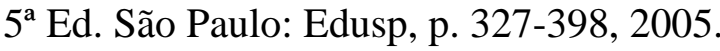

SEYSSEL, R. Um Estudo Histórico Perceptual: A Bandeira Brasileira Sem Brasil. Dissertação de Mestrado em Artes Visuais pela UNESP. São Paulo: Unesp, 2006.

VIDAL, J. W. B. De Estado Servil à Nação Soberana: civilização solidária dos trópicos. 2 ${ }^{\text {a }}$ Ed. Petrópolis/RJ: Editora Vozes, 1988. 